\title{
ASSESSMENT OF THE INFLUENCE OF INNOVATION AND IT MARKETS ON THE PARAMETERS OF THE REGIONAL ECONOMY
}

\author{
GARIPOVA N. Ekatarina ${ }^{1}$, KULIK N. Elena ${ }^{2}$, NABIEVA G. Larisa ${ }^{3}$ \\ ${ }^{I}$ Department of General Management of the Institute of Management, Economics and Finance, Kazan Federal University \\ (RUSSIA) \\ ${ }^{2}$ Department of General Management of the Institute of Management, Economics and Finance, Kazan Federal University \\ (RUSSIA) \\ ${ }^{3}$ Department of General Management of the Institute of Management, Economics and Finance, Kazan Federal University \\ (RUSSIA) \\ Emails: garipova_e_n@list.ru; 576301@rambler.ru; larisa-nabieva@yandex.ru
}

\begin{abstract}
The significant increase in the influence of innovation and information technologies in the modern world, including on economic processes, their constant interaction with classical markets of production factors, and accordingly the need to develop a methodology for assessing their mutual influence - all this has determined the purpose and tasks of research.

The article discusses the features of markets mutual influence of innovation and information technologies, as well as their impact on the economy of the region. Based on the conclusions, a methodology for quantifying this influence is proposed, which is characterized by simple and convenient application in the implementation of state regulation of the regional economy. The study is based on the analysis of statistical data for more than 20 years of the economy development of the Russian Federation and the Republic of Tatarstan and is highly representative. The results of the study allowed justifying the theoretical approach, to develop methodological and practical recommendations on diagnostics, assessment and forecasting of the impact of the two most important components of the modern industrial revolution 4.0 innovation and information technologies - on the stability and balance of the regional economy. The main product of the study is the system functional multi-sector model of the regional economy, which allows solving all the above-mentioned problems and problems in an optimal way.
\end{abstract}

Keywords: Development Economics, Macroeconomics, Innovation Market, IT Market, Regional Economy

JEL: 010

UDC: 005.332:001.895

332.14(470.41)

COBISS: SR-ID 28616457

\section{Introduction}

The relevance of the study is due to the set of currently existing characteristic features of the functioning of both Russian and a number of similar economic systems.

Firstly, the high degree of the process's instability taking place in the national economy.

Against this background, traditional tools for analyzing the economic situation do not allow a full picture of the changes taking place. In turn, the high turbulence of the processes 
taking place in the economy does not allow to ensure the construction of high-precision forecasts of the situation development and to carry out informed regional planning on the basis of them.

Secondly, there is insufficient clarity in the nature, mechanics, development and fading of imbalances and crises in the economy. These circumstances and non-monetary development cycles also add to the complexity of forecasting and planning processes.

Thirdly, in the light of the shift in the overall paradigm of global economic growth under the influence of the Fourth Industrial Revolution and the trend towards increased technologization and digitalization of various spheres of life, it is particularly important to determine the degree of interdependence of the functioning of regional economic systems from the sustainable development of innovation and information technology markets.

Thus, the study is aimed at developing a holistic vision and methodological tools for systemic multi-sector diagnostics of processes taking place in the regional economy, as well as an assessment of the mutual relationship between the most important parameters, which allows to explain the nature of "disturbances" in the regional economy in order to ensure the implementation of effective, adaptive, productive economic policy.

Analysis of classical and modern economic literature shows that problems of diagnostics, assessment and forecasting of influence of various economic phenomena on the balance of economic development of regions were quite widely considered both by foreign and domestic scientists. Existing theories and approaches to diagnosis, prediction, and management are based, in their bulk, on the methodology and approaches developed by J.M. Keynes [14].

Later, the model of economics by J.M. Keynes was developed in the writings of J. Hicks, A. Hansen, diverse approaches to the methodology of macroeconomic modeling were considered by the classics of economic thought: F. Kane, A. Marshall, L. Valras [17], V. Pareto, P. Samuelson [21], and Nobel Prize winners: R. Frisch, Y. Timbergen, S. Blacksmith, L. Klein, R. Solow, L.S. Schepley, E.E. Roth, W. Nordhouse, K. Shell.

A comprehensive analysis of the Russian economic literature to establish the existence of a systematic approach to assessing and predicting the mutual influence of various economic phenomena (especially with regard to the impact of innovation and information technologies on the sustainability and balance of the development of the modern economy) has revealed significant reserves in this area. Some aspects were covered in the works of S.A. Ashmanov [3], A.G. Aganbegyan, L.E. Basovsky [4], a little earlier - in the fundamental research of A.G. Granberg School, G.B. Kleiner School [15], in the works of V.V. Yegorov, M.R. Safiullin [20], S.A. Dyatlov [5], etc. Regional problems in the field of assessment of mutual economic phenomena were touched upon in the works of A.A. Anohin, V.P. Mozhin [19], in the studies of the Institute of Regional Economics Problems of the Russian Academy of Sciences, the Center for Advanced Economic Studies of the Academy of Sciences of the Republic of Tatarstan, the Institute of Social and Economic Research of the Ufa Federal Research Centre of the Russian Academy of Sciences, etc. Issues of scientific, technical and innovative activity were considered by G.A. Untura, A.E. Kogut, etc. [16]. The system of regional reproduction is analyzed, for example, in the works of A.I. Dobrinin, A.S. Marshalova and A.S. Novoselova.

Despite the significant contribution of scientists to the development of theoretical and methodological foundations of the influence of innovation and information technologies on the development of the modern economy, it should be emphasized that these issues have not been widely covered in modern literature, especially in Russian literature.

The study is aimed at the development of a holistic simulation and methodological tool for the construction of systemic multi-sector diagnostics of processes taking place in the regional economy, as well as an assessment of the mutual relationship between the most important parameters, which allows to explain the nature of "disturbances" in the regional economy in 
order to ensure the implementation of effective and productive economic policy. In this regard, we propose to use a modification of the system functional model of the market economy - a system functional multi-sector model of the economy considering the innovation market and the information technology market. The functioning general principle of the system functional multi-sector model of the market economy is shown in Figure 1.

The proposed new simulation tools allow to integrate cost, quantitative and qualitative characteristics of the innovation and information technology market into the modern economic system, which makes it possible to fully understand the nature, relationship and multiplicative wave effects of the interaction between the output of innovative products, inflation, employment, involvement of fixed production funds, investment processes on the volume of innovative products output. We believe that the proposed approach is a holistic concept of determining the place and role of the innovation and information technology market in the interaction system of classical markets, based on 14 new stable inter-market segments.

The identified new inter-market segments can be conditionally divided into three main groups: innovative inter-market segment, IT segment, innovation and information intermarket segment.

The innovative inter-market segment is an area of interaction and interplay between the innovation market and classical markets in the economic system.

IT-segment is formed due to the mutual relationship and resulting interdependence of the information technology market and classical markets.

Innovation and information inter-market segment is formed in the zone of interaction and interaction between the innovation market and the information technology market.

\section{Specifics of Functioning of the System Functional Multi-Sector Model of the Regional Economy}

The functioning of the innovative inter-market segment is determined by the interaction of the following identified new factors of interaction between the innovation market and classical markets.

The first inter-market segment was called the innovative return of fixed assets. It is a relationship between the capital market quantity (value of the fixed assets) and the innovation market value (volume of innovation output).

The next new segment is the impact of innovation prices, which describes the interdependence of innovation output and inflation. This segment is a consequence of the interaction between the innovation market and the commodity market. 


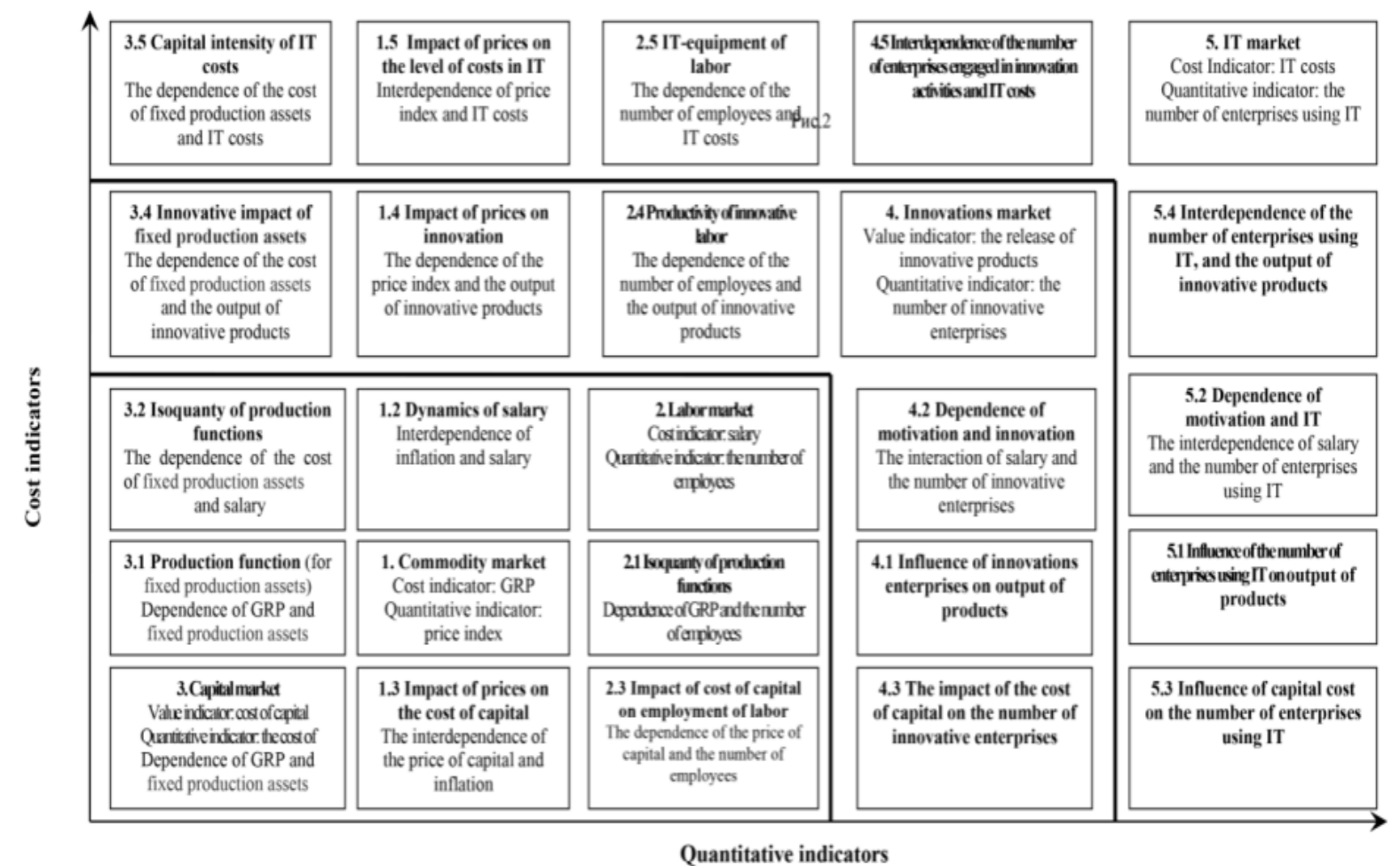

Fig. 1. The principle of functioning of the system functional multi-sectoral model of the regional economy

The innovation market here is represented by its value indicator - the volume of innovative products production, and the commodity market is represented by a quantitative indicator the inflation rate.

Such a new inter-market segment as productivity of innovative labor determines the mutual relationship between the number of employees and the volume of output of innovative products. In this case the interdependence of the market of innovations and its cost index (release of innovative products) and also the market of labor and its quantitative index (the number of labor) works.

The dependence of innovation and motivation, which is also among the new inter-market segments, is the interaction of the quantitative indicator of the innovation market - the number of innovative enterprises and the value of the labour market - the level of wages.

Another new segment in the innovative inter-market space is the impact of the number of innovative enterprises on the volume of production of the total product. This segment is formed as a result of interaction of quantitative indicator of innovation market (number of innovative enterprises) and value indicator of commodity market (volume of produced products).

The last new inter-market segment in the innovative inter-market space is the impact of the cost of capital on the number of enterprises using innovation. Accordingly, the indicators forming it are the number of enterprises using innovation (quantitative indicator of the innovation market) and the rate of interest (value indicator of the capital market).

Analysis of the formation and functioning of innovative inter-market space will allow determining the peculiarities of the reproduction process of innovation both of the region and the country, to give an economic and mathematical description of the identified interdependence and to make appropriate recommendations in terms of the formulation of the main provisions of economic policy.

The development and construction of a system functional multi-sector model of the economy considering the innovation market and the information technology market allowed to identify, along with innovative inter-market space, another important such element - IT- 
space. IT-space is formed due to functioning and interaction of information technology market (IT-market) and classical markets of factors of production.

The developed new concept of determining the interplay of the information technology market and classical markets describes the interaction of the following discovered new factors:

1. Capital intensity of IT expenses. It is a relationship between the capital market quantity (value of the fixed assets) and the value of the information technology market (cost of information technology);

2. The interplay of the IT price and cost index. As in the innovation space, this segment is a consequence of the interaction between the commodity market and the information technology market. The commodity market here is represented by a quantitative indicator - the inflation rate, and the IT market - by its value indicator the volume of IT costs;

3. IT-armament of labor is the dependence of the number of employed and costs of IT, which are a quantitative indicator of the labor market and a value indicator of the information technology market, respectively;

4. The interdependence of motivation and the number of enterprises using IT is the mutual relationship between the number of enterprises using information technologies (a quantitative indicator of the IT market) and the level of wages (a value of the labour market);

5. The impact of capital costs on the number of enterprises using the IT-inter-market segment, which is a relationship between the quantitative indicator of the information technology market and the value of the capital market;

6. The impact of the application of information technologies on the volume of production of the total product reflects the results of interaction between the information technology market (and its quantitative indicator - the number of enterprises using IT) and the commodity market (and its value - the total volume of produced products).

Analysis and evaluation of the identified new inter-market segment with the participation of the information technology market will make it possible to draw a conclusion on the trajectory of development of information technology markets in the national and regional economy. The construction of a modified IT-market inclusion system model of the economy of the Russian Federation will make it possible to identify more stable interaction between the capital market and the IT-market than similar interaction in the regional economy of the Republic of Tatarstan.

The use of a modified system functional model of the economy as a tool for assessing the impact of innovation and information technology markets on the economy of the region, allowed determining how these markets actually interact and how this interaction will develop in the forecast period. In the course of the study, the following new zones of intermarket interaction were proposed and justified, which are part of the innovation and information intermarket space formed in the zone of interaction and interaction between the innovation market and the information technology market: interdependence of the number of enterprises engaged in innovation and costs in IT; and the interdependence of the number of enterprises using IT and the output of innovative products.

The relationship between the number of enterprises engaged in innovation and the costs in IT arises from the interaction between the IT-market value (IT costs) and the innovation market quantity (the number of enterprises engaged in innovation). The inverse interdependence of the IT-market quantity (the number of enterprises using IT) and the value of the innovation market (the volume of production of innovative products) give us the interdependence of the number of enterprises using IT and the production of innovative products. 
In order to present our theoretical and methodological provisions in a visual form and to work out their main directions, we will calculate the system functional multi-sector model of the economy with the inclusion of the market of innovation and information technologies, presented in the next section of the study.

\section{Innovation Market in the System Functional Multi-Sector Model of the Regional Economy}

In the previous sections of the study, we have described a new simulation toolkit that allows for the organic integration of the cost, quantity and quality characteristics of the innovation market into the modern economic system. We believe that this will make it possible to better understand the nature, relationship and multiplicative wave effects of the interaction between the production of innovative products, inflation, employment, the involvement of fixed production funds, investment processes on the volume of production of innovative products. Consider the proposed holistic concept in order to determine the place and role of innovation market in the system of interaction of classical markets, having built a system functional multi-sector model of a market economy with the innovation market inclusion for the economy of the Republic of Tatarstan (Figure 2).

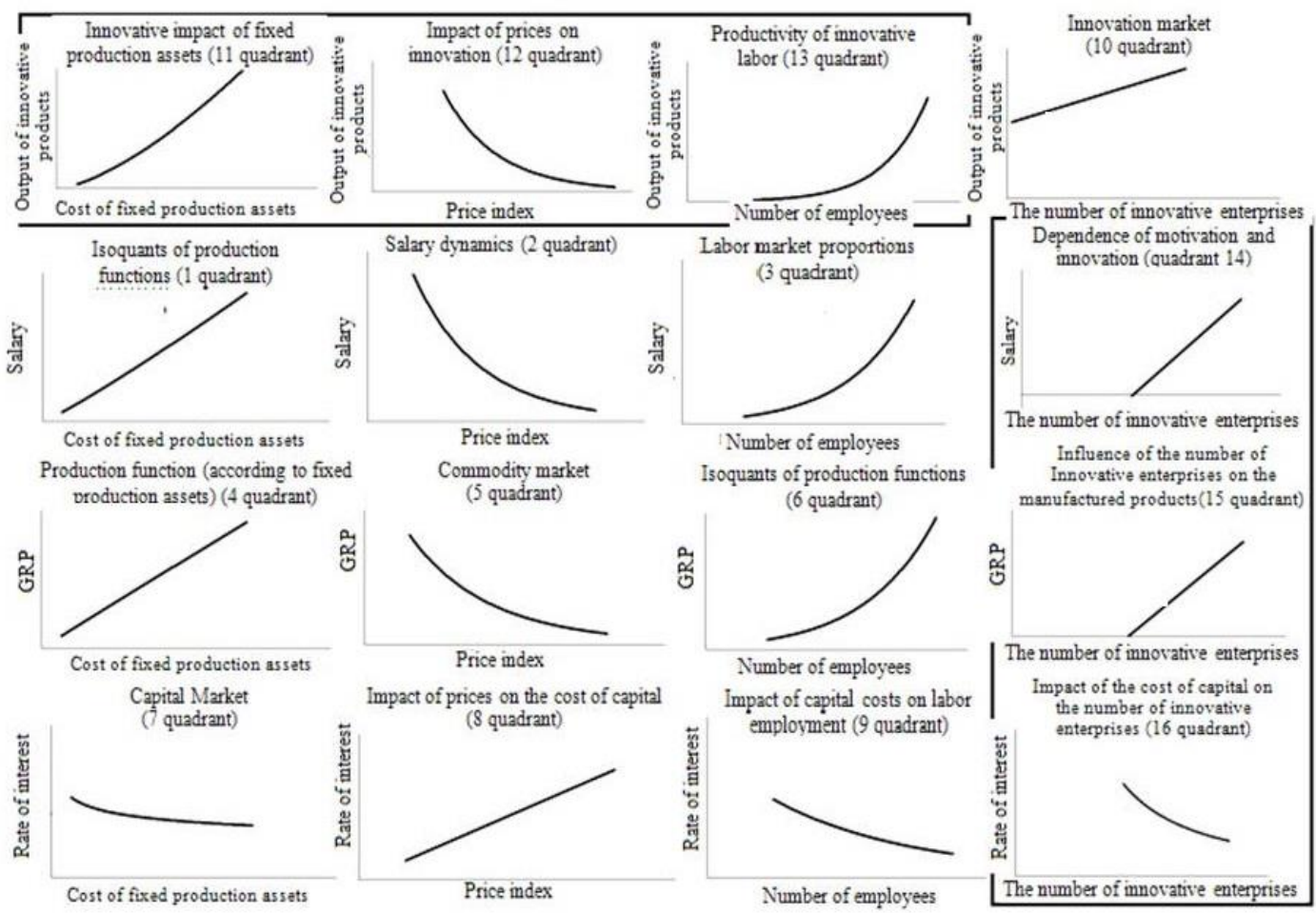

Fig. 2. General view of the system functional multi-sectoral model of the economy of the Republic of Tatarstan considering the innovation market

The figure shows new segments in the inter-market innovation space. We will analyze the formed segments and the market of innovation in the regional economy.

The innovation market (10 quadrants) is characterized by a high degree of dependence (R2 $=0.7799$ ) of the production of innovative products and the number of innovative enterprises, unlike the innovation market of the Russian Federation, and is described by a linear function:

$$
y=0,1867 x+99,716
$$

Where: $\mathrm{y}$ - Volume of innovation products output;

$\mathrm{x}$ - Number of innovative enterprises. 
It can be noted that with the increase in the number of innovative enterprises, the volume of production of innovative products is also increasing. In general, this conclusion is quite logical and presents a wide range of opportunities in the regulation of the innovation market.

In the analysis of the interrelationship of the innovation return of the fixed assets (value of the fixed assets and volume of the innovation output (11 quadrant)), it can be noted that the dependence is stable $(\mathrm{R} 2=0.9214)$ and is described by the power function:

$$
y=7 E-08 x 1,4811
$$

Where:

$\mathrm{y}$ - Volume of innovation products output;

$\mathrm{x}-$ Fixed assets cost.

The increase in the value of the fixed assets causes a steady increase in the volume of innovative products, and at a higher rate. This makes it possible to influence the output of innovative products by varying some aspects of the management of fixed assets (e.g., depreciation policies).

The interdependence between the output of innovative products and the price index, representing the impact of prices on innovation and presented in the 12 quadrants, is represented by the power function:

Where:

$$
y=1516,2 x^{-26,05}
$$

$\mathrm{y}$ - Volume of innovation products output;

$\mathrm{x}$ - Price index.

and has a low approximation ratio $(\mathrm{R} 2=0.5376)$, indicating that an increase in the price index may not necessarily lead to a drop-in innovation output.

The productivity of innovative labor or the revealed interdependence of the number of employed and the volume of output of innovative products (13 quadrant) looks transparent: as the number of employed in the economy increases, the volume of output of innovative products increases and vice versa. This relationship is stable, as evidenced by a relatively high approximation coefficient $(\mathrm{R} 2=0.7205)$ :

$$
y=3 E-100 x^{31,217}
$$

Where:

$\mathrm{y}$ - Volume of innovation products output;

$\mathrm{x}$ - Number of employees.

Thus, it can be concluded that varying the level of employment in the economy can also influence the innovation of products produced in the region.

It should be noted that the value of the impact of the innovation market on the regional economy of the Republic of Tatarstan has achieved relatively stable results, unlike the national economy of the Russian Federation. However, the quantitative indicator - the number of innovative enterprises - revealed a low-stable level of dependence on the market introduced into the model and the classical system model.

Consider the dependence of motivation and innovation, represented by the mutual relationship between the number of innovative enterprises and the wage (14 quadrants). Our research has shown that with the increase in the number of innovative enterprises, wages are also increasing in linear mathematical dependence:

Where:

$$
y=321,75 x-27739
$$

y - Salary;

$\mathrm{x}$ - Number of innovative enterprises.

However, the approximation ratio is relatively small here $(\mathrm{R} 2=0.7361)$, which does not reveal clear control tools in this combination. The narrow capacity of government statistics in the field of accounting for the innovation market does not give us additional opportunities to 
find other tools that could be incorporated into the systemic functional model of the market economy, considering the innovation market.

A similar situation is observed in the analysis of the impact of the number of innovative enterprises on the produced products (15 quadrants):

$$
y=19509 x-2 E+06
$$

Where:

$\mathrm{y}$ - The volume of the made products;

$\mathrm{x}$ - Number of innovative enterprises.

The study found that the growth of the number of innovative enterprises causes an increase in the volume of produced products, but a sufficiently high value of the approximation coefficient $(\mathrm{R} 2=0.7559)$ suggests that an additional instrument of influence on the state of the economy of the republic has been formed.

In the analysis of the impact of the cost of capital on the number of innovative enterprises (16 quadrants), an unstable $\left(\mathrm{R}^{2}=0.4583\right)$ interdependence was revealed, which describes the power function:

$$
y=12209 x-1,422
$$

Where:

$\mathrm{y}$ - Interest rate;

$\mathrm{x}$ - Number of innovative enterprises.

The reduction of the rate of interest causes an understandable growth of the number of innovative enterprises, which certainly gives clear guidelines in the formation of credit policy of the region.

With the help of the system functional multi-sector model of the market economy, empirical significant differences of national and regional inter-market spaces have been revealed, and it has been proved that the growth of the number of innovative enterprises is observed with the simultaneous reduction of wages and production volumes in the Russian Federation, which indicates a pronounced imbalance in macro-development, when innovation and their development do not have a serious impact on the development of the economy.

\section{Information Technology Market in the System Functional Multi-Sector Model of Regional Economy}

On the basis of the new simulation tools proposed in the previous sections of the dissertation study, we have identified an additional new functional inter-market segment - ITsegment, characterized by stable relationships of cost, quantitative and qualitative parameters of the information technology market and "classical markets". Within the framework of the identified new inter-market space, we have developed and justified a new mechanism for determining the place and role of the information technology market in the system of interaction between classical markets.

In order to characterize the peculiarities of the reproduction process of the region and the country and the economic and mathematical description of the identified interdependence, we will build a system functional multi-sector model of the economy, including the information technology market.

We will analyze the formed segments and directly IT-market in the regional economy (Figure 3).

The 10-quadrant information technology market is characterized by the following key aspects: With an increase in the number of enterprises using information technology in their operations, the total cost of IT has a marked tendency to increase. In the mathematical expression, this relationship can be mapped as a linear function: 


$$
y=0,0735 x+3177
$$

Where: $\mathrm{y}$ - Costs of IT;

$\mathrm{x}-$ Number of enterprises using IT.

This relationship is quite stable: $\mathrm{R} 2=0.7909$.

In addition, there are persistent $(\mathrm{R} 2=0.9722)$ relationships between the IT market and the capital market (11 quadrant), represented by the capital intensity of IT costs. As the cost of fixed assets increases, IT costs are expected to increase in the following proportion:

$$
y=1 E-05 x^{1,4176}
$$

Where: $\mathrm{y}-$ Costs of IT;

$\mathrm{x}-$ Fixed assets cost.

This phenomenon can be explained by the fact that the increase in the share of the use of information technologies contributes to the partial removal of fixed assets from the production process, which leads to an increase in the level of technological efficiency of the products.

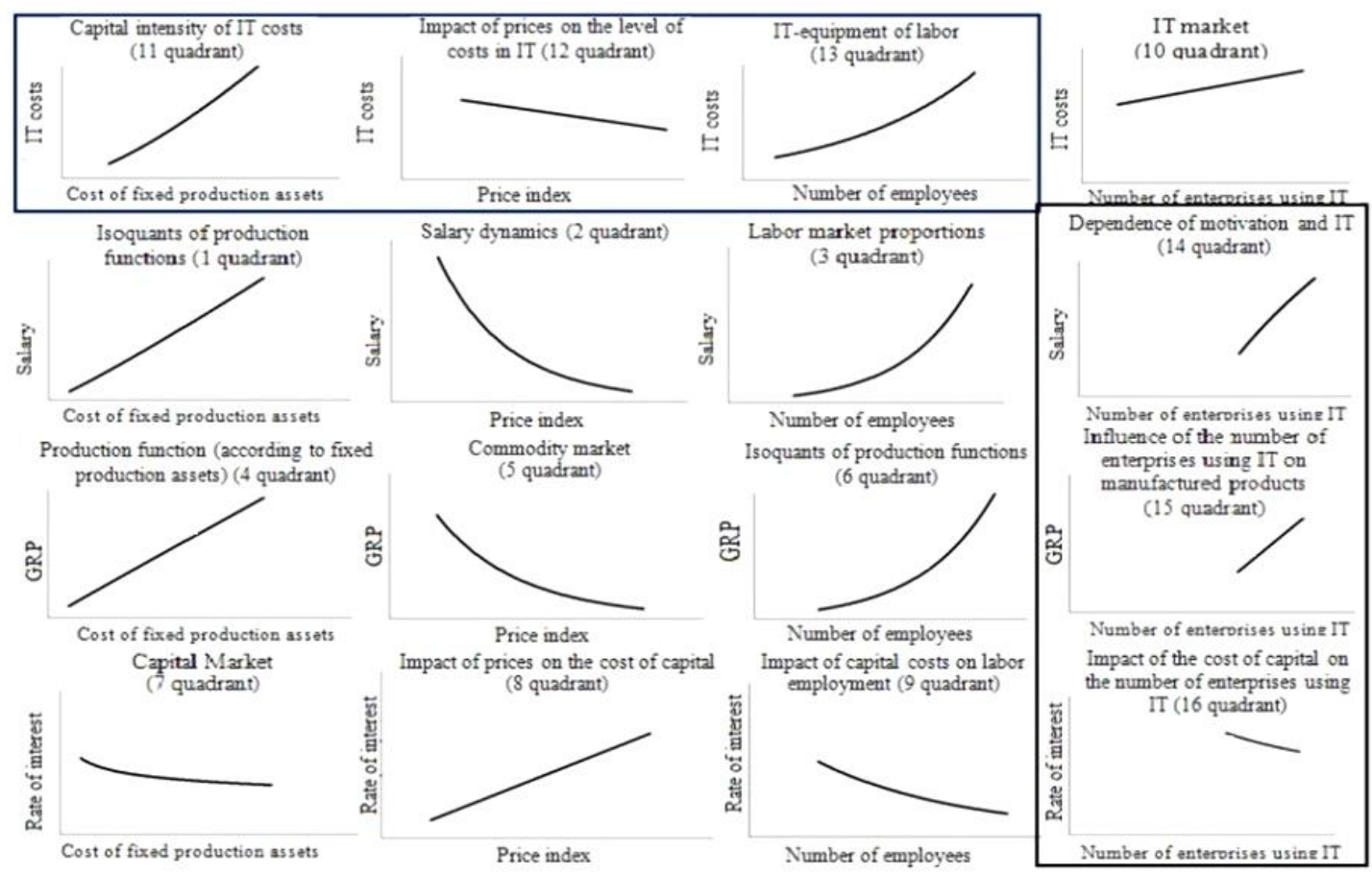

Fig. 3. General view of the system functional multi-sector model of the economy of the Republic of Tatarstan, including the IT market

In the analyzed period there is a very weak $(\mathrm{R} 2=0.079)$ relationship between the index of prices and the level of costs for information technologies (12 quadrants), displayed by the indicator of the impact of prices on the level of costs in IT:

$$
y=-83033 x+104169
$$

Where: $\mathrm{y}-$ Costs of IT;

$\mathrm{x}$ - Price index.

However, there is a downward trend in information technology costs as the price index increases.

Analysis of the obtained segment of IT-armament of labor showed that with the growth of the number of employed in the economy there is an increase in the level of costs in information technologies (13 quadrant):

$$
y=3 E-51 x^{16,738}
$$

Where: $\mathrm{y}-$ Costs of IT;

$\mathrm{x}$ - Number of employees. 
However, this dependence is unstable because the approximation factor is 0.282 . Here, as in the case of fixed production funds, we can deal with the complication or simplification of the technological chain.

It should be noted that the interlinkages between the information technology market and its value index and classical markets in the economy of the Republic of Tatarstan are mainly low-tolerance, which does not allow to rely fully on established dependencies in planning and forecasting the actions of the authorities in the field of economic regulation.

We will analyze the relationship between the quantitative indicator of the information technology market and classical markets.

In the analyzed period there was a rather stable $(\mathrm{R} 2=0.9734)$ dependence of motivation and IT (level of wages and number of enterprises using information technologies in their activities), presented in the 14th quadrant. This dependency is described by the logarithmic function:

$$
y=50413 \ln (x)-400672
$$

Where: y - Salary;

$\mathrm{x}$ - Number of enterprises using IT.

At the same time, the increase in the number of enterprises using IT causes wage increases.

Stable dependence $(\mathrm{R} 2=0.944)$ is also observed in the analysis of the impact of the number of enterprises using IT on manufactured products (15 quadrants):

$$
y=703,18 x-2 E+06
$$

Where: $\mathrm{y}-$ The volume of the made products;

$\mathrm{x}-$ Number of enterprises using IT.

According to the data received, the more enterprises resort to the use of information technologies in their activities, the more products are produced in the Republic. This conclusion, in our opinion, is one of the most important results of work on the introduction of new markets into the systemic model of the market economy.

Finally, in the 16 quadrants of the system model of the market economy with the inclusion of the IT market, there is a low $(\mathrm{R} 2=0.2716)$ level of the cost influence of capital on the number of enterprises using information technologies in their activities:

$$
y=787,47 x^{-0,531}
$$

Where: $\mathrm{y}$ - Interest rate;

$\mathrm{x}-$ Number of enterprises using IT.

However, with the reduction in the percentage rate, the number of such enterprises is increasing.

This fact should not be ignored in the forecasting of the economic situation and public planning.

\section{Conclusions}

In the system functional model of the economy with the inclusion of the innovation market and the IT market, a number of main trends can be traced.

Thus, it can be noted that in general, the model for the Republic of Tatarstan shows less stable interdependence of IT-market and classical markets in the regional economy compared to the national economy. First of all, it concerns the relationship between quantitative indicators of IT-market and classical markets, where in the national economy there is stable interdependence, and in the regional economic system along with stable (dependence of motivation and IT, the influence of the number of enterprises using IT on produced products) interdependence there is low stability - influence of capital cost on the number of enterprises using IT. 
Despite the presence of low-tolerance and unstable interdependence in models, the following leverage can be distinguished from the above in the system functional multi-sector model of the economy, including the innovation and IT markets.

First, the sustainable production function of the innovation market suggests a close relationship between the volume of innovation output and the cost of the fixed assets. It can also be surely argued that the growth of the number of employees in the economy allows increasing the output of innovative products (stable ratio of isoquant of production function).

In addition, there is a rather strong dependence of the innovative products output on the price index.

The identified relationships of the information technology market when it is included in the system functional model of the market economy make it possible to speak about the following key leverage. First, confident interdependence was evident in the construction of the ITmarket production function, which indicates an increase in information technology costs with an increase in the cost of fixed assets. In addition, there is a steady dependence of wages on the number of enterprises using IT: the increase in the number of such enterprises causes wage increases and vice versa. In addition, the number of enterprises using information technologies affects the volume of produced products: the growth of such enterprises causes an increase in the volume of production in the republic. These conclusions make it possible to make appropriate adjustments to the process of forming recommendations on the construction of the economic policy of the Republic of Tatarstan.

\section{Acknowledgements}

The work is performed according to the Russian Government Program of Competitive Growth of Kazan Federal University.

\section{REFERENCES}

[1] Aganbegian, A.G., \& Granberg, A.G. (1985). Scientific and technological progress and acceleration of socio-economic development. Moscow, M.: Economy.

[2] Aleskerov, F.T., \& Kiselgof, S.G. (2012). Nobel Prize winners - 2012: Lloyd Shepley and Alvin Roth. The Economic Journal of HSE (pp. 433-443).

[3] Ashmanov, S.A. (1983). Qualitative theory of multi-sector models of economic dynamics. Moscow, M.

[4] Basovsky, L.E. (2004). Market forecasting and planning. Moscow, M.: "INFRA - M".

[5] Dyatlov, S.A., \& Maryanenko, V.P. (2012). Theoretical and methodological basis of analysis of the national innovation system. Education Economy (\# 3, pp. 73-80).

[6] Glaziev, S. (2009). World economic crisis as a process of substitution of technological modes. VOPROSY ECONOMIKI 3.

[7] Glazyev, S. Yu. (2000). Once again on the same rake? To the assessment of the Strategy of Development of the Russian Federation up to 2010. Fund "Center for Strategic Development"). The Russian Economic Journal, pp. 10-41.

[8] Glazyev, S. Yu. On the strategy of development of the economy of Russia. http://www.glazev.ru/scienexpert/

[9] Granberg, A. About (1985). Dynamic models of national economy. Moscow, M.: Economy.

[10] Granberg A. About (2002). Strategies of Russian macroregions: Methodological approaches, priorities and ways of implementation. Novosibirsk 9, pp. 199-202.

[11] Granberg, A. G., Suslov, V. I., \& Suspitsyn. S. A. (2007). Multi-regional systems: economic and mathematical research. Novosibirsk, Sib. Nauk. Ed 371.

[12] Kaneva, Maria, A., \& Galina, A. Untura. (2018). Evolution of Theories and Empirical Models of a Relationship between Economic Growth, Science and Innovations (Part 2). World of Economics and management 1, pp. 5-17.

[13] Kantorovich, L.V. (2011). Chosen compositions. mathematic-economic works. Novosibirsk, Novosibirsk: Science.

[14] Keynes, J.M. 2009. Chosen works. Moscow, M.: Eksmo. 
[15] Kleiner, G. Efficiency of mesoeconomic systems in transition. http://vasilievaa.narod.ru/ptpu/5_6_02.htm

[16] Kogut, A. E., \& Rohchin, V. S. (1995). Information basis for regional socio-economic monitoring. St. Petersburg: ISSI Academy of Sciences.

[17] Marshall, A. (1997). Principles of economic science. Moscow, M.: Progress publishing house.

[18] Moskovkin, V.M. Unknown Semen Kuznets: studying in Kharkov. http://n-t.ru/n1/ek/kuznets.htm

[19] Mozhin, V.P., \& Gladyshev, A.N. (1982). Territorial and production complexes of the USSR: Probl. formations and development. Moscow, M.: Politizdat.

[20] Safiullin, M. R. (1996). Methodology of strategic management of the economic system through investments and employment (on the example of the Republic of Tatarstan). Kazan.

[21] Samuelson of Item (1997). Economy. Moscow, M.: NPO ALGON, "Mechanical engineering".

[22] Tinbergen, J. (1971). Some improvements to partial cross-sectoral balance. Regional Science on the Placement of Productive Forces 3: pp. 57-62. Novosibirsk-Irkutsk.

[23] Tinbergen, Y., \& Boss, X. (1967). Mathematical models of economic growth. Moscow, M.: Progress.

[24] Unified inter-agency information and statistical system. https://www.fedstat.ru

\section{Article history:}

Received 16 September 2020

Accepted 18 November 2020 